\title{
Using handheld pXRF to study medieval stained glass: A methodology using trace elements
}

\author{
Laura W. Adlington ${ }^{1}$ and Ian C. Freestone ${ }^{1}$ \\ ${ }^{1}$ UCL Institute of Archaeology, 31-34 Gordon Square, London, WC1H 0PY
}

\begin{abstract}
The surfaces of 30 pieces of glass from panel $3 b$ of the Great East Window of York Minster (1405-1408 CE) were analyzed by handheld portable X-ray fluorescence (pXRF) and small samples from the same pieces were analyzed by electron microprobe (EPMA). Comparison of the two methods reveals significant divergences which are not systematic, particularly for elements lighter than Ti. Rather than a problem with pXRF calibration or correction software, the non-systematic error is attributable to the presence of a thin surface layer of weathered glass. Analysis of the depths of X-ray generation indicate that virtually all X-rays characteristic of $\mathrm{Ca}$ and $\mathrm{K}$ are generated within the top $50 \mu \mathrm{m}$ of the glass. However, for heavier elements such as $\mathrm{Rb}, \mathrm{Sr}$ and $\mathrm{Zr}$, most emitted X-rays are generated below $100 \mu \mathrm{m}$. Using pXRF data for the heavier elements, it is possible to replicate the compositional groupings identified by quantitative EPMA. White glass in the window is likely to have originated in England, while colored glasses were probably obtained from the Continent. The alkali contents of the green and yellow glasses appear to have been manipulated to generate their colors. Glass which is medieval in technology but not original to the panel was identified. In particular, zirconium proved a useful indicator of glassmaking regions, and rubidium and strontium were more sensitive to differences between batches, which has interesting implications for future work.
\end{abstract}

\section{INTRODUCTION}

Stained glass was an important element of ecclesiastical architecture in the Middle Ages, and its production was underpinned by a significant industry. However, our understanding of the chaîne opératoire of a stained glass window is limited, due to the restricted nature and poor preservation of the relevant documentation (Marks, 1993).

Scientific analysis has the potential to facilitate our understanding of key aspects regarding the life history of stained glass windows, including glass sources, glassmaking technology, and the identification of evidence of conservation post-construction. Unfortunately, the analysis of windows is inhibited by their architectural context, which makes sampling the windows impossible unless dismantled. Thus, in situ techniques such as handheld (portable) Xray fluorescence spectrometry (pXRF) have great potential for the study of stained glass windows.

There are considerable obstacles in the application of pXRF for medieval stained glass, in particular the deterioration of medieval glass resulting in a layer of altered composition, greatly affecting surface analyses by pXRF. This problem will be discussed along with a consideration 


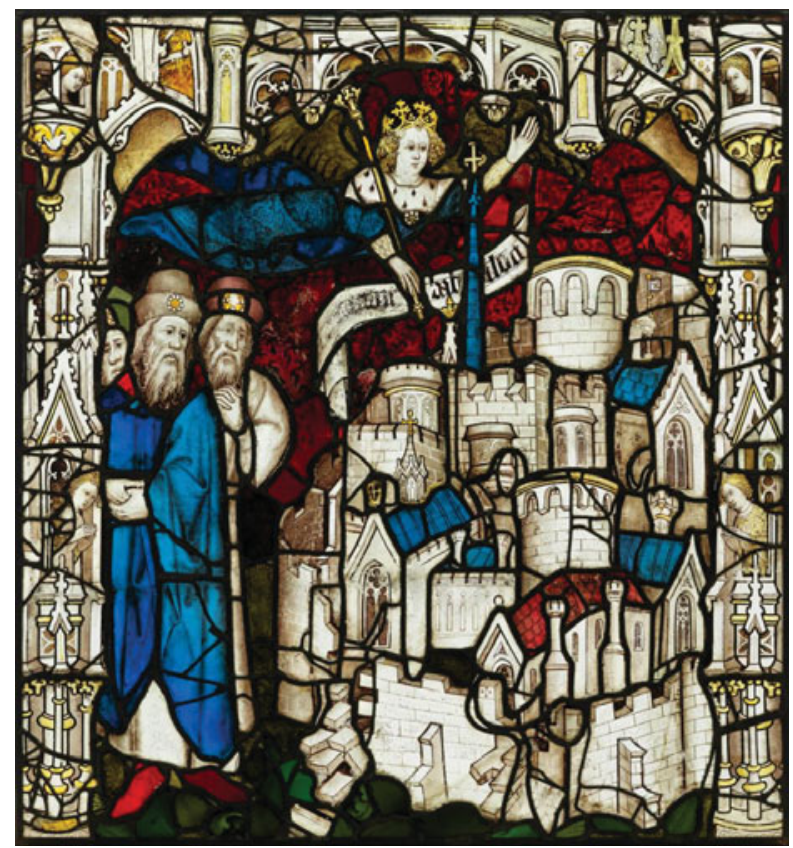

Figure 1. Panel 3b of the Great East Window of York Minster, depicting a scene from Revelations 18, the destruction of Babylon. Photo: The York Glaziers Trust: reproduced with the kind permission of the Chapter of York.

of the depth of analysis of the technique in order to suggest an alternate methodology for application of $\mathrm{pXRF}$ to medieval stained glass windows.

In the present study, it has also been possible to take samples from the window in question, as it has been dismantled as part of a major conservation project. Fully quantitative compositional data collected by electron microprobe analysis will be used to discuss the glass recipes and technologies that supplied the window, as well as the identification of previous conservation efforts and presence of non-original glass. In comparison, the pXRF data will also be examined to determine whether it can be used to reveal the same information.

\section{MATERIALS AND METHODS}

One panel (3b, Figure 1) from the Great East Window of York Minster was selected for this study. The Great East Window, which was constructed 1405-1408, is considered to be the masterpiece of the influential glass-painter, John Thornton (Marks, 1993; French, 2003). The window has been the subject of an extensive conservation project named York Minster Revealed, during the course of which the window has been dismantled and the individual glass pieces 


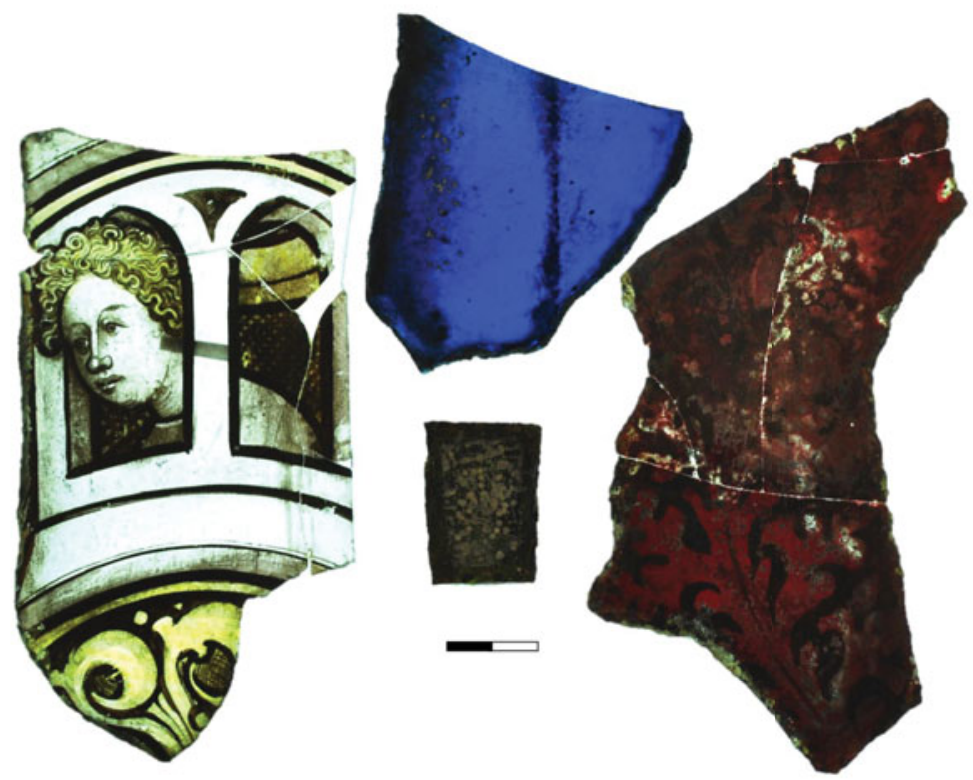

Figure 2. Four glass pieces from panel 3b, showing different levels of deterioration for the different colors present in the panel: clockwise starting at the far left: white (internal surface), blue (internal), red (internal), and green (external). Generally the white glass was in excellent condition with only minor evidence of deterioration, whilst the green and yellow glasses were heavily pitted. The red glass shows some loss of the red flash layer. Scale bar shows centimeters.

removed from the lead cames holding them together. The glass was therefore accessible for sampling, and for analysis by pXRF using a test stand.

Thirty pieces of glass were chosen for analysis by both methods: thirteen white (i.e., colorless with a very pale "natural" tint of blue or green), nine blue, five red-flashed, two green and one yellow. The analyses by pXRF were carried out on site at the York Glaziers Trust conservation studio. The glass was analyzed directly on the surface using an Innov-X Systems/Olympus Delta Premium DP-4000 handheld portable X-ray fluorescence spectrometer (pXRF) attached to a test stand, using the built-in "Soils" mode with 20s per setting (i.e., "beam") for a total time of 60 s per analysis. Beam 1 operates at $40 \mathrm{kV}$ and $89 \mu \mathrm{A}$ with a copper filter, Beam 2 operates at $40 \mathrm{kV}$ and $52 \mu \mathrm{A}$ with a $2 \mathrm{~mm}$ aluminum filter and Beam 3 operates at $15 \mathrm{kV}$ and $68 \mu \mathrm{A}$ with a $0.1 \mathrm{~mm}$ aluminum filter. Areas that were clear of surface treatment or corrosion were chosen, so some analyses were on the external surface and others on the internal surface. Corning Museum Reference Glass D (Brill, 1999; Adlington, in press) was used as a secondary standard. Preliminary calibrations have been applied to the data for eight elements (Ti, $\mathrm{Co}, \mathrm{Ni}, \mathrm{Cu}, \mathrm{Zn}, \mathrm{Rb}, \mathrm{Sr}$, and $\mathrm{Zr}$ ) based on the analysis of multiple glass standards. Results are reported as elements parts per million. 
Samples were taken from the glass pieces and mounted in epoxy resin with the crosssection exposed and polished to $1 \mu \mathrm{m}$. They were initially examined using a Leica DM $4500 \mathrm{P}$ LED polarizing microscope equipped with a camera. The resin blocks were then vacuum-coated with carbon and analyzed using a JEOL JXA-8100 electron probe micro-analyzer with three attached wavelength dispersive spectrometers (EPMA-WDS) operating with an accelerating voltage of $15 \mathrm{kV}$, a beam current of $50 \mathrm{nA}$, count time of $50 \mathrm{~s}$, a working distance of $10 \mathrm{~mm}$ and on area dimensions determined by $800 \mathrm{x}$ magnification giving an analyzed area of approximately 150 by $110 \mu \mathrm{m}$, The mean results for 7 individual analyzed areas on each sample are reported as weight percentages and have not been normalized. Corning Glasses A, B and D were used as secondary standards. The samples were also examined and imaged using a Hitachi S-3400 scanning electron microscope in back-scattered mode.

\section{RESULTS}

Examination of the glass showed that there were varying levels of deterioration between the colors. The white glasses showed only minor evidence of deterioration, with some micropitting near painted areas. The blue and red glasses had minor to moderate amounts of deterioration, while the green and yellow glasses showed significant pitting and loss of a glassy surface (Figure 2). The deterioration of the glass pieces sometimes varied between their internal (i.e., facing indoors) and external surfaces; generally, the white glass was in better condition on the external surface, while the green and yellow were in better condition on the internal surface. All of the glass were homogeneous and colored throughout the glass, with some exceptions: the red glasses were flashed with a thin layer of red glass on the surface of a white glass body (Type B, Kunicki-Goldfinger et al., 2014), and the yellow glass also had bands of colorless glass near the surface of a yellow/green glass base.

\section{Chemical characterization by EPMA}

The mean compositions of each color group are reported in Table 1. All of the glasses are of the potash-lime-silica type, consistent with medieval compositions. There are compositional differences distinguishing the white glass from the colored glasses: the white glasses have 58 wt $\% \mathrm{SiO}_{2}, 7 \% \mathrm{MgO}$, and $15 \% \mathrm{CaO}$, while the colored glasses have $46-51 \%$ silica, c. $4 \% \mathrm{MgO}$ and $20-25 \% \mathrm{CaO}$ (Figure 3a; cf. Freestone et al., 2010). There is one exception, a red-flashed glass (R5) that is of a low-magnesia, low-lime composition; this suggests that while this glass piece may still be of medieval manufacture, it is from a window of a different date and was used to patch up the panel during conservation of the window in the centuries following 1408 .

The red-flashed glasses were analyzed on the white glass base, though analysis on a red flash showed that elevated copper was responsible for the coloration, as anticipated (KunickiGoldfinger et al., 2014). The blue glasses are colored by around $0.08 \%$ cobalt oxide, with associated high $\mathrm{Zn}, \mathrm{Fe}$ and $\mathrm{Cu}$. A high-zinc source of cobalt is typical of the period (Gratuze et $a l ., 1995)$. The yellow and green glasses are colored by an additional $2 \%$ iron oxide and it is noteworthy that no added copper was detected in the green. Furthermore the green and yellow glasses differ from the other colors in their elevated $\mathrm{K}_{2} \mathrm{O}$, at around $16 \%$ as opposed to $11 \%$ (Table 1; Figure 3b). 
Two white glasses, W2 and W13, were evidently made from a very similar recipe to the other white glasses, but with small differences in composition (in silica, and in potash for W13). One red glass, R3, is similarly made with the same recipe of the other reds, but has minor differences in its lime, soda and phosphate concentrations.

\begin{tabular}{|c|c|c|c|c|c|c|}
\hline & White & Blue & Red & R5 & $\begin{array}{l}\text { Green/ } \\
\text { Yellow }\end{array}$ & $\begin{array}{c}\text { Rel. } \\
\text { Acc. \% }\end{array}$ \\
\hline $\mathrm{Na}_{2} \mathrm{O}$ & 2.22 & 1.11 & 1.32 & 0.40 & 1.50 & 8.9 \\
\hline MgO & 6.94 & 3.94 & 4.19 & 4.75 & 4.21 & -5.2 \\
\hline $\mathbf{A l}_{2} \mathbf{O}_{3}$ & 1.32 & 1.62 & 1.64 & 1.86 & 1.64 & -1.2 \\
\hline $\mathrm{SiO}_{2}$ & 57.63 & 51.27 & 50.12 & 51.47 & 46.18 & 0.4 \\
\hline $\mathrm{P}_{2} \mathrm{O}_{5}$ & 3.37 & 2.92 & 3.37 & 3.81 & 4.04 & 1.4 \\
\hline $\mathrm{SO}_{3}$ & 0.18 & 0.15 & 0.22 & 0.18 & 0.26 & -2.9 \\
\hline Cl & 0.33 & 0.04 & 0.05 & 0.35 & 0.04 & 0.9 \\
\hline $\mathbf{K}_{2} \mathbf{O}$ & 10.13 & 11.41 & 10.83 & 18.99 & 15.81 & 0.4 \\
\hline $\mathrm{CaO}$ & 15.14 & 23.83 & 25.14 & 14.78 & 20.61 & -2.2 \\
\hline $\mathrm{TiO}_{2}$ & 0.09 & 0.12 & 0.12 & 0.13 & 0.14 & 13.7 \\
\hline MnO & 1.43 & 1.20 & 1.17 & 1.11 & 1.46 & -5.5 \\
\hline $\mathrm{Fe}_{2} \mathrm{O}_{3}$ & 0.48 & 0.89 & 0.53 & 0.37 & 2.70 & -6.2 \\
\hline $\mathrm{CoO}$ & $<0.03$ & 0.08 & $<0.03$ & $<0.03$ & $<0.03$ & BD \\
\hline $\mathrm{CuO}$ & 0.04 & 0.16 & 0.08 & 0.05 & 0.06 & -4.1 \\
\hline $\mathrm{ZnO}$ & 0.04 & 0.14 & 0.04 & $<0.03$ & 0.04 & -25.4 \\
\hline PbO & 0.07 & 0.19 & 0.20 & $<0.03$ & 0.06 & -7.0 \\
\hline Total & 99.71 & 99.55 & 99.47 & 98.77 & 99.23 & \\
\hline
\end{tabular}

Table 1. The mean compositions in weight percentage of the color groups in the glass from panel $3 \mathrm{~b}$ of the Great East Window of York Minster, as measured by EPMA. R5, a low-lime, low-magnesia red-flashed glass, was identified as non-original and is reported separately. The green and yellow glasses are reported together because they are so similar in composition, except for their iron concentrations (Green glasses: $2.5 \mathrm{wt} \% \mathrm{Fe}_{2} \mathrm{O}_{3}$; Yellow glass: $3.1 \mathrm{wt} \% \mathrm{Fe}_{2} \mathrm{O}_{3}$ ). The relative accuracy is given in the final column, based on analyses of Corning D.

\begin{tabular}{lrrrrrr}
\multicolumn{2}{c}{ White } & Blue & Red & R5 & $\begin{array}{c}\text { Green/ } \\
\text { Yellow }\end{array}$ & $\begin{array}{c}\text { Rel. } \\
\text { Acc. \% }\end{array}$ \\
\cline { 2 - 7 } Ti & 708 & 1020 & 829 & 1102 & 1070 & 7.9 \\
Co & 25 & 768 & 49 & 53 & 155 & -8.1 \\
$\mathbf{N i}$ & 53 & 66 & 47 & 69 & 49 & 3.4 \\
$\mathbf{C u}$ & 120 & 1123 & 465 & 187 & 338 & -0.5 \\
$\mathbf{Z n}$ & 393 & 1379 & 1379 & 206 & 319 & -0.9 \\
$\mathbf{R b}$ & 225 & 323 & 300 & 283 & 363 & 3.3 \\
$\mathbf{S r}$ & 491 & 693 & 735 & 524 & 594 & -10.0 \\
$\mathbf{Z r}$ & 59 & 114 & 108 & 71 & 113 & 5.0
\end{tabular}

Table 2. The mean concentrations in ppm of the color groups for selected elements measured by pXRF. The relative accuracy is given in the final column, based on analyses of Corning D. 

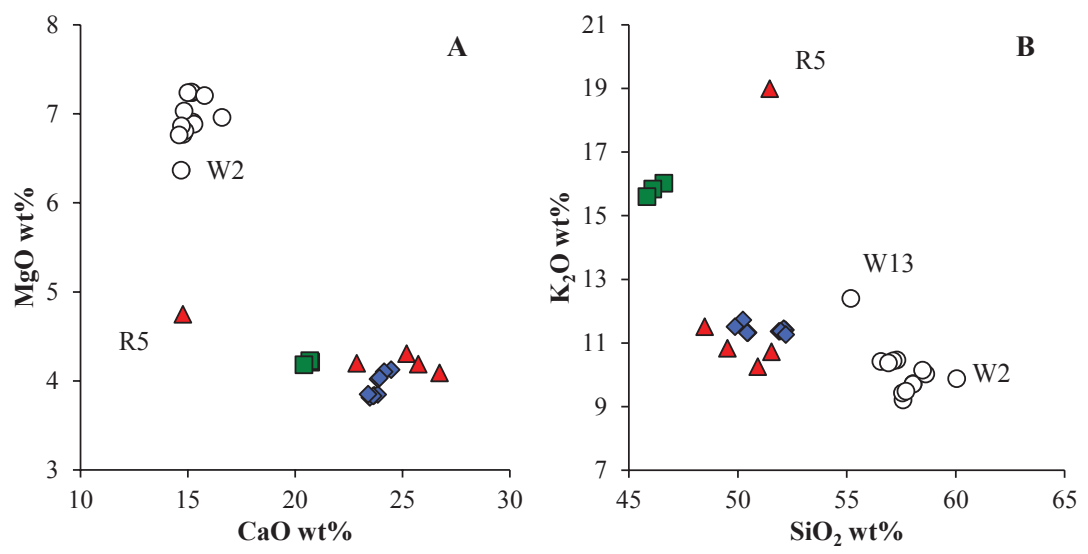

OWhite

$\diamond$ Blue

$\Delta$ Red

$\square$ Green/Yellow

Figure 3. Magnesia and lime concentrations (3a, left) and potash and silica concentrations ( $3 \mathrm{~b}$, right) for the panel $3 \mathrm{~b}$ glass, showing two compositionally distinct groups comprising the white glass and the colored glasses. The outlying red glass R5 is unlikely to be original to the panel. W2 and W13 are also marked; these glasses are very similar to the main group of white glass, but with some small differences.

\section{Chemical characterization by $\mathrm{pXRF}$}

The mean composition of each color group as analyzed by pXRF are reported in Table 2 . The configurations chosen for the pXRF analyses prohibited the analysis of elements lighter than phosphorus, thus excluding silica ${ }^{2}$. Other major elements were poorly analyzed, in particular potassium; the precision on calcium was also unsatisfactory (Figure 4). Other light elements, such as phosphorus, sulfur, and chlorine, similarly had poor precision and were incompatible with the EPMA analyses (Figure 4). The scatter on these data indicates that they are unlikely to be reliable even if the pXRF was fully standardized on reference materials. However, the heavier trace elements showed better precision allowing the characterization of different groups of glass. The white glass can be separated from the colored glasses due to its lower titanium, chromium, rubidium, strontium and zirconium. Rubidium and strontium, in particular, show three groups comprising the white glass, the blue and red glasses, and the green and yellow glasses (Figure 5a), the same groups recognized using EPMA. The blue glass also show higher concentrations of cobalt, zinc, and copper; the green and yellow glasses have higher concentrations of iron. The red glasses were analyzed on both the white base (exterior) and the red flash (interior); the red flash had higher concentrations of copper as well as iron, nickel and chromium.

Three glasses, W2, W13 and R3, are consistent with the other glasses in their Zr concentrations but exhibit small differences in their $\mathrm{Sr}$ concentrations (Figure 5b). 

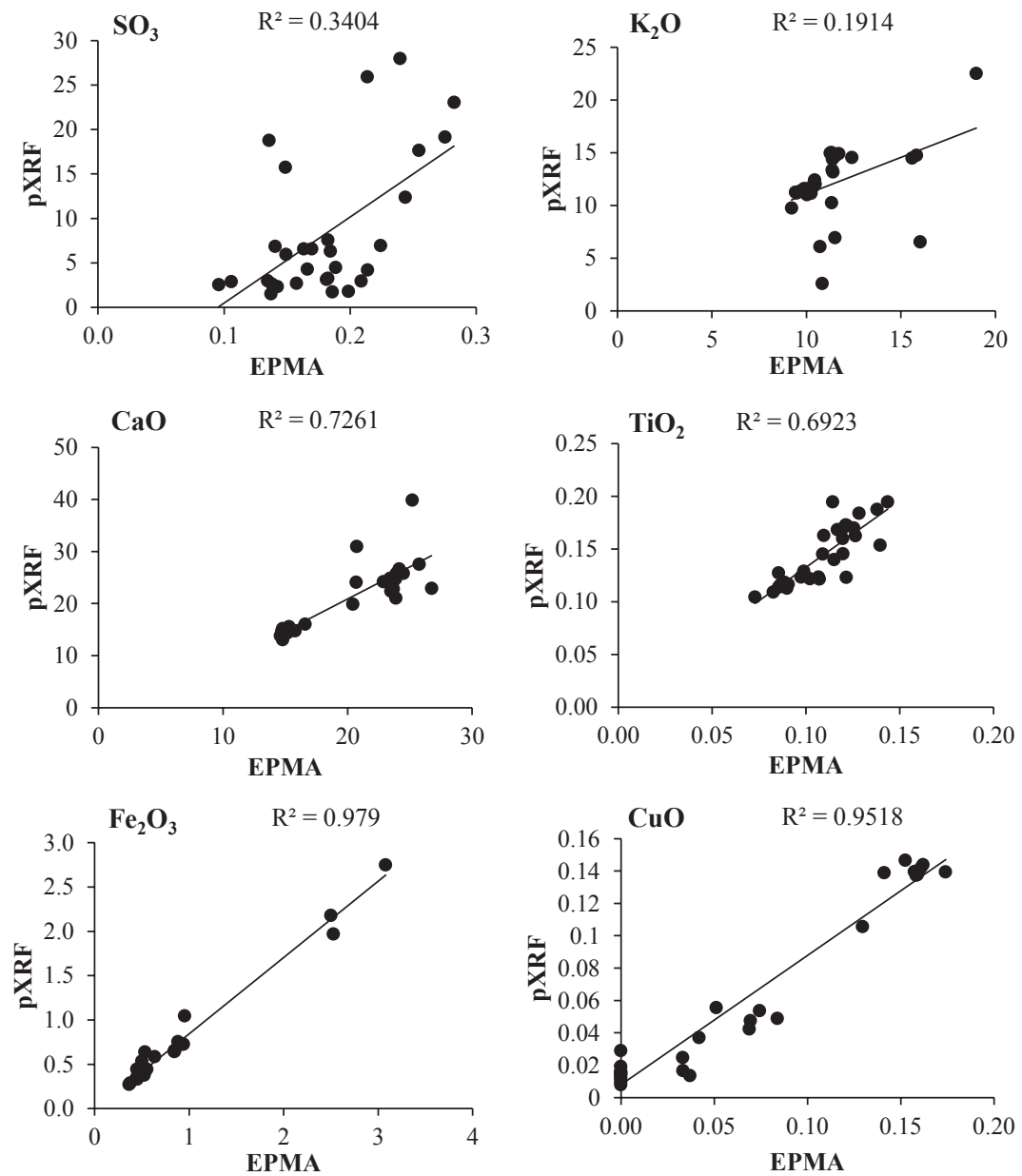

Figure 4. Biplots showing concentrations of selected elements as measured by pXRF and EPMA, showing poor precision of the surface analyses by $\mathrm{pXRF}$ for lighter elements. Iron and copper are better measured and show better linear agreement between the methods. The limits of detection of EPMA is likely responsible for some of the scatter in the copper graph, as well as titanium. All concentrations are reported as oxide weight percentages, calculated using stoichiometry. Of the six elements compared here, only the pXRF results for titanium and copper have been calibrated. 

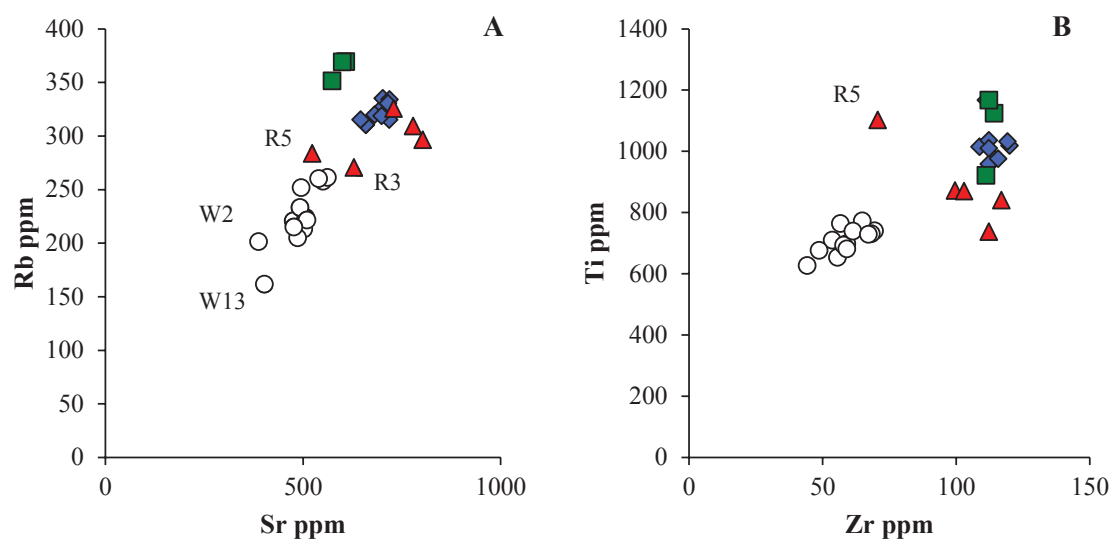

OWhite

$\diamond$ Blue

$\triangle$ Red

$\square$ Green/Yellow

Figure 5. Biplots showing concentrations of selected trace elements in the various glass groups. The trace elements rubidium and strontium (5a, left) and zirconium ( $5 \mathrm{~b}$, right) differentiate between the major glass groups identified using the EPMA major element data. Analyses of titanium, in Figure 5b, has been affected by surface conditions for some glass pieces, most notably the green glass showing lower concentrations.

\section{DISCUSSION}

\section{Deterioration and the depth of analysis}

Handheld pXRF can be a tremendously useful technique in a field that is inhibited by limitations on sampling, however its use is not without criticism. The primary problem with $\mathrm{pXRF}$ in archaeology is not the technique, but the suitability of the material for analysis - it must be homogeneous, criteria that many archaeological materials fail to meet without sampling and sample preparation.

Window glass is an ideal material for pXRF, being flat and level, and a homogeneous material. Previous work, notably the work conducted by David Dungworth and his colleagues at English Heritage (2011) has been very successful in the application of pXRF to the study of postmedieval colorless window glass on historic houses in the UK. Scott et al. (2012) found that pXRF adequately identified different glass types (e.g., soda, potash, HLLA) from drastically different dates, but that differentiating glass recipes within a glass type was problematic. The approach depends upon the assumption that the glass surface has an identical composition to the bulk. This is not necessarily valid as medieval stained glass may have paint and silver stain on the surface, and even more problematic, it is very prone to deterioration. Dungworth encountered this problem in a subset of medieval glass, and recognized the superior precision of heavy trace 
elements for these glasses (2012; see also Van der Snickt et al., 2016). Therefore, a methodology focused on the use of trace elements in pXRF analysis is a focus of the present paper.

The composition of medieval glass makes it one of the least durable glasses of premodern times. Starting from about the eighth century (Wedepohl, 2003), glassmakers in Europe used wood ash, or the ashes of terrestrial plants such as ferns and bracken, as the alkaline flux to bring down the melting temperature of the silica sand for easier working, resulting in a glass that is relatively low in silica and high in potassium and calcium. The addition of alkaline and alkaline earth ions disrupts the silica network through the creation of non-bridging oxygens (NBOs) and formation of weaker ionic bonds between $\mathrm{NBO}$ and $\mathrm{M}^{+}$and $\mathrm{M}^{2+}$ ions in place of the stronger Si-O covalent bonds between the silica tetrahedra (Pollard and Heron, 1996).

Furthermore, the bond between $\mathrm{K}^{+}$and $\mathrm{NBO}$ is weaker than that between $\mathrm{Na}^{+}$and $\mathrm{NBO}$, due to its larger volume and resultant lower field strength, and therefore $\mathrm{K}^{+}$is leached out of the glass more easily than $\mathrm{Na}^{+}$. The low silica concentrations and the disruption of the silica network by high alkali concentrations, and secondarily the presence of $\mathrm{K}^{+}$rather than $\mathrm{Na}^{+}$, results in a glass that is particularly prone to deterioration (Fernández-Navarro and Villegas, 2013). This phenomenon, in particular the importance of the silica content to deterioration processes, is evidenced by the varying deterioration of the glass in the present study; the white glass, with the highest silica content, is in the best condition, while the green and yellow glasses, which are low in silica and high in potash, are in particularly poor condition.

The deterioration of the glass is a complex phenomenon that is dependent on several factors including not only the properties of the glass, but also its environment or exposure to certain conditions (Newton, 1982). This relationship can also be observed in the glass of panel $3 \mathrm{~b}$, as glass of different colors (i.e., compositions) exhibited different weathering behaviors on the internal and external surfaces (Figure 2) due to the very different environmental conditions. Common deterioration mechanisms on in situ stained glass windows are firstly the leaching of modifying ions, in particular the weakly bonded $\mathrm{K}^{+}$, from the surface of the glass, and secondly the formation of corrosion products including sulfates, chlorides and organic compounds (Newton, 1982; Schreiner et al., 1999; Melcher and Schreiner, 2006).

The effect of a layer of altered composition on surface analyses by pXRF can be understood through a consideration of the depth of analysis. This is dependent on the specific configuration of the spectrometer (the energy of the primary radiation, and the angles of take-off and incidence), on the density of the sample material, and on the energy of the element's characteristic fluorescent radiation (Potts, Williams-Thorpe and Webb, 1997). Equation 1, adapted from Potts, Williams-Thorpe and Webb (1997) and Kaiser and Shugar (2012), may be used to calculate the depth, $x$, from which a percentage of fluorescent X-rays, $I_{x} / I_{0}$, are emitted from a sample. To calculate the critical depth, $x_{c}$, from which $99 \%$ of the fluorescent X-rays are emitted, $I_{x} / I_{0}$ is set to 0.99 .

$$
x=-\frac{\ln \left(1-\frac{I x}{I_{0}}\right)}{\left[\rho \cdot \mu_{n e t}\right]}
$$

$\rho$ Is the density of the sample and $\mu_{\text {net }}$ is the bulk mass attenuation coefficient, defined by Equation 2 (Potts, Williams-Thorpe and Webb, 1997). It is the sum of two terms, the first describing the attenuation of the primary radiation penetrating the sample at an angle of $\psi_{1}$ (the incidence angle, between the excitation source and the sample); and the second describing the 
attenuation of the fluorescent X-rays travelling out of the sample to the detector at an angle of $\psi_{2}$ (the take-off angle, between the detector and sample: Figure 6).

$$
\mu_{n e t}=\frac{\mu_{\text {source }}}{\sin \psi_{1}}+\frac{\mu_{K \alpha}}{\sin \psi_{2}}
$$

The mean average of the original glass was used to estimate the composition and density of the sample material matrix. The mass attenuation coefficients were obtained using the NIST website. $^{1}$

As the depth of analysis is dependent upon the energy of the characteristic X-rays of each element, different elements are read from different depths within the sample; heavier elements with higher energy characteristic X-rays are read from deeper within the glass. The depth function is logarithmic (Figure 7), meaning a greater percentage of the emitted X-rays will originate from the more shallow layers (see Table 2). Even in the present case, in which much of the weathered layer has been removed in conservation, there is a leached layer of altered composition (Figure 8) which has an observable effect on the lighter elements as seen by the comparison between EPMA and pXRF (Figure 4). However, pXRF analyses of prepared standard reference materials under the same operating conditions show a good linear correlation with the given values (Figure 9), indicating that the errors in the analysis of the medieval glass are an artifact of the corroded glass surface and not, for example, due to the conduct of the analyses in air.

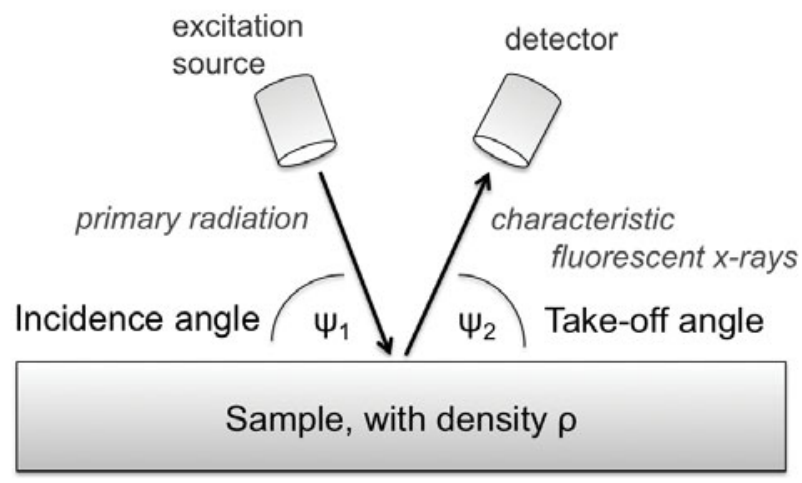

Figure 6. An illustration of the parameters of XRF analysis, including the identification of the angles, $\psi_{1}$ and $\psi_{2}$, which are variables in Equation 2. This equation describes both the primary radiation penetrating the sample at angle $\psi_{1}$ and the characteristic fluorescent X-ray travelling out of the sample to the detector at angle $\psi_{2}$. 

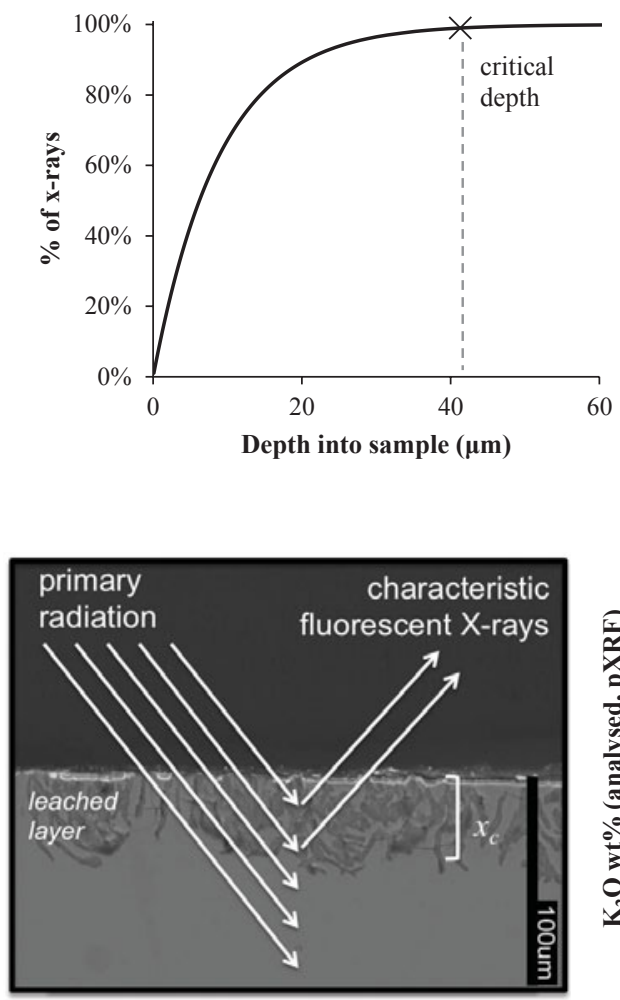

Figure 8. Illustration of the critical depth of analysis, $x_{c}$, of potassium and calcium, imposed on a back-scattered electron image of a glass from Panel 3b (R3), which shows the extent of the leached layer and the resultant effect on surface analysis.
Figure 7. Graph of the logarithmic function that describes the percentage of the characteristic X-rays, $I_{x} / I_{0}$, that originate from within a depth, $x$, in a sample. The critical depth, from which $99 \%$ of X-rays originate, is marked with a cross. This graph illustrates the depth of analysis of potassium and calcium. The average composition of the original glass from panel $3 \mathrm{~b}$ was used to approximate the sample density, and the parameters of the $\mathrm{pXRF}$ analysis were used in the calculation.

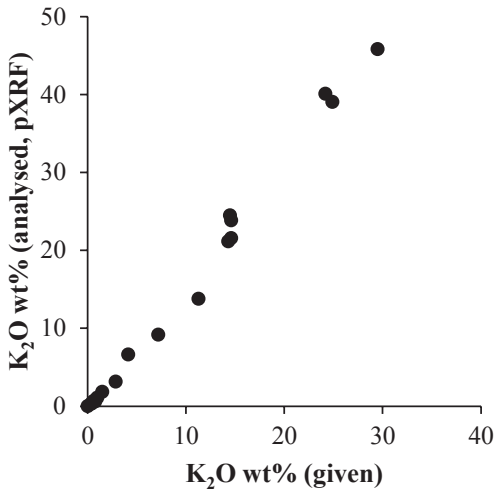

Figure 9. Biplot showing the analysis of 20 reference glasses against their given values, showing a good linear correlation. Nonsystematic error in the data (see Figure 4) is therefore attributed to the presence of corrosion on the surface.

By selecting heavy elements with higher energy characteristic X-rays, which are generated in deeper areas of the glass, we can see an improvement in the data. In particular, the elements rubidium, strontium and zirconium (with critical depths of 872, 999, and $1325 \mu \mathrm{m}$ respectively; Table 3) were well measured by pXRF. These elements are related to the raw materials of the base glass, with zirconium added through the sand raw material, and rubidium and strontium related to the potash- and lime-rich wood (or fern/bracken) ash. Similarities in ionic charge and radius allow these trace elements to substitute for major elements ( $\mathrm{Rb}$ for $\mathrm{K}, \mathrm{Sr}$ 


\begin{tabular}{l|rrrrr}
\multicolumn{1}{c}{$\mathbf{I}_{\mathbf{x}} / \mathbf{I}_{\mathbf{0}}$} & \multicolumn{1}{c}{$\mathbf{K}$} & $\mathbf{C a}$ & $\mathbf{R b}$ & \multicolumn{1}{c}{$\mathbf{S r}$} & $\mathbf{Z r}$ \\
\cline { 2 - 6 } $99 \%$ & 41.3 & 41.3 & 872 & 999 & 1325 \\
$90 \%$ & 20.6 & 20.7 & 436 & 500 & 662 \\
$75 \%$ & 12.4 & 12.4 & 262 & 301 & 399 \\
$50 \%$ & 6.2 & 6.2 & 131 & 150 & 199 \\
$25 \%$ & 2.6 & 2.6 & 54.4 & 62.4 & 82.8
\end{tabular}

Table 3. The depths, in micron, at which different percentages of the characteristic X-rays are read for relatively light elements potassium and calcium, and heavier elements rubidium, strontium and zirconium. Calculations are based on the analytical parameters of the current study and a sample of the average composition of the panel $3 \mathrm{~b}$ glass.

for $\mathrm{Ca}$, and $\mathrm{Zr}$ for $\mathrm{Ti}$,) in common minerals and therefore enter the glass via the raw materials rich in those major elements (the Goldschmidt Rules, revised by Ringwood, 1955; also cf. Shannon, 1976).

Therefore, the analyses of selected, relatively heavy, trace elements hold the most promise for a study of medieval glass by $\mathrm{pXRF}$ - they are analyzed well due to their higherenergy characteristic X-rays, and should relate information about the raw materials in the same way that the major elements do.

A further consideration for analysts is the thickness of the glass being analysed. In the present study, the glass of panel $3 \mathrm{~b}$ was generally $2 \mathrm{~mm}$, which exceeds the critical depth of analysis of the heavy trace elements. Depending on the spectrometer parameters and the composition of the glass being analysed, corrections may need to be made if the critical depth exceeds the sample thickness (cf. Kaiser and Shugar, 2012).

\section{Significance of glass groupings}

Both the pXRF and EPMA data indicate the presence of three main compositional groups of glass in panel $3 \mathrm{~b}$ of the Great East Window. The white glass has high $\mathrm{MgO}$ and low $\mathrm{CaO}$, while the colored glass has high $\mathrm{CaO}$ and low $\mathrm{MgO}$ (Figure 3a), suggesting the use of different wood/fern ashes; this is supported by the pXRF data for $\mathrm{Sr}$ and $\mathrm{Rb}$ (Figure 5a). There are also differences in some trace elements analyzed by pXRF, for example $\mathrm{Zr}$ and $\mathrm{Ti}$ (Figure $5 \mathrm{~b}$ ), which are elements characteristic of glassmaking sands. These differences suggest that the white glass and the colored glasses were made in very different regions, which is consistent with the view that colored window glass was imported, as the production of colored window glass was not known in England in the medieval period (Marks, 1993). While it is not possible from the present data to infer the origins of the white glass, our on-going work using trace element and isotopic analyses has produced good matches for the white glasses in English glass production sites.

Potash and lime concentrations distinguish the blue and red-flashed glasses $\left(11 \% \mathrm{~K}_{2} \mathrm{O}\right.$, $24 \% \mathrm{CaO})$ from the green and yellow $\left(16 \% \mathrm{~K}_{2} \mathrm{O}, 21 \% \mathrm{CaO}\right)$. The close similarity between the red and blue glasses suggests that they were provided by a single production center, perhaps one which specialized in colored glass production.

The yellow and green glasses, which are almost identical to each in major element composition, also differ from the blues and reds with elevated $\mathrm{Fe}_{2} \mathrm{O}_{3}$, at around $2.7 \%$ which appears to have been the component responsible for the color. The higher $\mathrm{K}_{2} \mathrm{O}$ appears to suggest 
that perhaps the green and yellow glasses were from a different production center than the other colors. However, model calculations involving the removal of $8 \%$ excess $\mathrm{K}_{2} \mathrm{O}+\mathrm{Fe}_{2} \mathrm{O}_{3}$ from the green and yellow glasses produce a base glass composition that is very similar to the base glass of the blue and the red. It therefore seems likely that the yellows and greens were produced in the same region as the blues and reds excepting that additional $\mathrm{K}_{2} \mathrm{O}$ was added to the iron-colored glasses. The potash source was Rb-poor (Figure 10). As is well known, $\mathrm{Fe}^{2+}$ absorbs strongly in the red end of the spectrum to give a blue coloration. $\mathrm{Fe}^{3+}$ on the other hand gives a yellow, while greens are generated at intermediate $\mathrm{Fe}^{3+} / \mathrm{Fe}^{2+}$ ratios (Weyl, 1951; Bamford, 1977). The addition of about $5 \% \mathrm{~K}_{2} \mathrm{O}$ would have increased the basicity of the melt, favoring the formation of $\mathrm{Fe}^{3+}$ and the production of a yellow or green color. Furthermore, it would have lowered the temperature at which the glass had to be melted, again favoring the oxidation of the iron and the production of yellows and greens over blues. The yellow glass was probably produced at lower temperatures, or in a less smoky furnace, than the green. The practice of modifying the potash content of the glass, or possibly of selecting a base glass richer in potassium, to produce oxidized colors, as far as we are aware has not previously been recognized in medieval glass. It suggests a degree of sophistication in the manipulation of color which is beyond that normally attributed to medieval glassmakers.

Three glasses, W2, W13 and R3, were made using recipes very similar to the other white and red glasses respectively, but showed small differences in composition that suggest that while they were possibly made by the same glassmaking production center as the other glasses, their production took place at a different time. It is known that glaziers and conservators over the centuries had a practice of repairing windows with glass from other windows, and it is possible that this is how these glasses, and the low-lime, low-magnesia R5, were introduced into the panel; alternatively, they could be from within the Great East Window itself. In regards to the painting style, W2 and W13 are painted in a different style and are likely infills from another window glazed at a different time (not by Thornton), whereas R3 is consistent with the rest of the window. The similarity of W2 and W13 to other white glasses suggest that York Minster had a steady source of white glass.

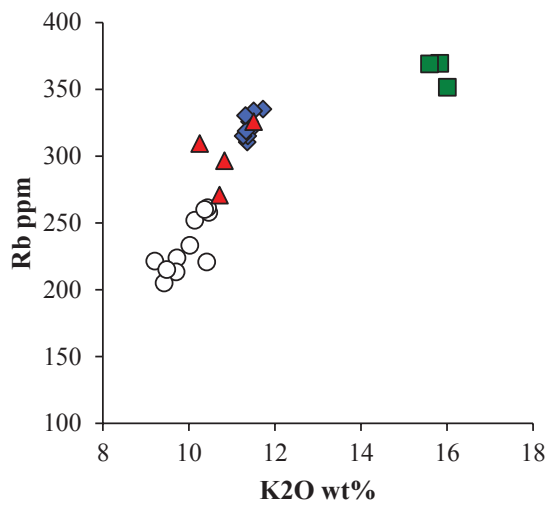

Figure 10. Biplot of rubidium concentrations (pXRF) against potash concentrations (EPMA) for the original glass from panel $3 \mathrm{~b}$. The additional potash source used for the green and yellow glasses added minimal rubidium to the composition.

OWhite

$\diamond$ Blue

$\Delta$ Red

$\square$ Green/Yellow 


\section{Handheld pXRF for medieval stained glass}

The trace elements, in particular rubidium, strontium and zirconium, are useful indicators of glass compositions and differentiate between glass types. Zirconium is indicative of the sand source, and can be used to differentiate glass from different production sources or regions. Rubidium and strontium appear to be more sensitive, showing even slight differences between glass pieces that were made with the same recipes but from different batches or furnace campaigns. The potential for $\mathrm{Rb}$ and $\mathrm{Sr}$ to tell information about batches is being utilized in ongoing work, and some of these preliminary results were presented at the MRS Fall Meeting and will be published in a forthcoming publication.

It is anticipated that when $\mathrm{pXRF}$ is used without the benefit of sampling for laboratory analysis, it will be difficult to interpret glass types without the major element concentrations and it will be impossible to compare to other published data without a database of trace elements. However, when it is impossible to sample the glass, the analysis of trace elements by pXRF provides a way to study the different sources of glass and glassmaking technology, and to identify non-original glass.

\section{CONCLUSIONS}

Fully quantitative EPMA analysis of a panel from the Great East Window of York Minster has yielded important information on glass groupings, provenance and past repairs. Although the use of compositional analysis of stained glass has until now been relatively restricted due to the problem of obtaining samples, where a window is dismantled as part of the conservation process, the opportunity should be taken as a matter of course to remove small samples from under the leaded areas for microanalysis.

Removal of the window leads is not required for many conservation interventions, and many windows are unlikely to be conserved for decades or longer. Recourse to portable methods is therefore likely to be essential. If used in an informed manner, portable X-ray fluorescence can yield useful information which can be related to the quantitative data. It is unlikely that it will be possible to generate fully quantitative data for elements lighter than titanium due to the presence of a leached layer even on glass which has apparently been cleaned. However, trace elements which generate $\mathrm{X}$-rays with higher energies, such as $\mathrm{Rb}, \mathrm{Sr}$ and $\mathrm{Zr}$ appear much more robust and allow the separation of groups and outliers which correspond to those identified with fully quantitative methods on fresh samples. In the present study, it was possible to identify all of the significant groupings seen with EPMA, but it was not possible to recognize the higher potassium which is likely to have been significant in generating the yellows and greens.

In the present study the $\mathrm{pXRF}$ instrument was not standardized and the concentrations of even the better-determined elements can only be regarded as semi-quantitative. Without the quantitative data EPMA on the same glasses, it would therefore be unsafe to relate the pXRF data to previously recognized groups. Our next step therefore will be to standardize the pXRF instrument for trace analysis and compare the results with LA-ICP-MS data on the same medieval glasses. 


\section{ACKNOWLEDGEMENTS}

We would like to thank the Dean and Chapter of York Minster and Sarah Brown, Director of the York Glaziers Trust, for providing access to the glass. Thank you to Kevin Reeves from the UCL Wolfson Archaeology Science Laboratories for performing the EPMA analyses, and to Nick Teed, Laura Tempest, and María Teresa Plaza for their help and advice. We are also grateful to the reviewers for their helpful comments. This study was supported by a UCL international studentship to Laura Adlington and developed out of previous work supported by the Leverhulme Trust to Ian Freestone. Participation in the MRS Fall Meeting was supported by the Society of Archaeological Sciences and UCL Institute of Archaeology funding.

\footnotetext{
${ }^{1}$ The NIST website resource (http://physics.nist.gov/PhysRefData/Xcom/html/xcoml.html) was used to obtain the mass attenuation coefficients, $\mu_{\text {source }}$ and $\mu_{K \alpha}$. The mean average composition of the glass was submitted as the matrix material

${ }^{2}$ The built-in Soils mode on the Innov-X/Olympus DP-4000 does not quantify elements lighter than phosphorus. The light element beam,running at $15 \mathrm{kV}$ does produce spectra including elements such as silicon, but no effort was made to quantify these elements due to the problems with analysing light elements that are discussed in this paper.
}

\section{REFERENCES}

Adlington, L. W. (in press) 'The Corning Archaeological Reference Glasses: New Values for "Old" Compositions', Papers from the Institute of Archaeology.

Bamford, C. R. (1977) Colour generation and control in glass. Amsterdam: Elsevier.

Brill, R. H. (1999) Chemical analyses of early glasses. Corning, NY: Corning Museum of Glass.

Dungworth, D. (2011) 'The value of historic window glass', The Historic Environment, 2(1), pp. 21-48. doi: 10.1179/175675011X12943261434567.

Dungworth, D. (2012) 'Historic windows: Investigation of composition groups with nondestructive pXRF', Glass Technology: European Journal of Glass Science and Technology Part A, 53(5), pp. 192-197.

Fernández-Navarro, J.-M. and Villegas, M.-Á. (2013) 'What is Glass? An Introduction to the Physics and Chemistry of Silicate Glasses', in Janssens, K. (ed.) Modern Methods for Analysing Archaeological and Historical Glass. Chichester, UK: John Wiley \& Sons, pp. 1-22. Available at: http://onlinelibrary.wiley.com/book/10.1002/9781118314234.

Freestone, I. C., Kunicki-Goldfinger, J. J., Gilderdale-Scott, H. and Ayers, T. (2010) 'Multidisciplinary Investigation of the Windows of John Thornton, Focusing on the Great East Window of York Minster', in Shepherd, M. B., Pilosi, L., and Strobl, S. (eds) The Art of Collaboration: Stained-Glass Conservation in the Twenty-First Century. London: The International Committee of the Corpus Vitrearum for the Conservation of Stained Glass, pp. 151-158.

French, T. (2003) York Minster: The Great East Window. Oxford: Oxford University Press (Corpus Vitrearum Medii Aevi: Great Britain, Summary Catalogue 2).

Gratuze, B., Soulier, I., Barrandon, J.-N. and Foy, D. (1995) 'The origin of cobalt blue pigment in French glass from the thirteenth to the eighteenth centuries', in Hook, D. R. and Gaimster, D. R. M. (eds) Trade and Discovery: Scientific Study of Artefacts from Post- 
medieval Europe and Beyond. London: British Museum (British Museum Occasional Paper), pp. 123-133.

Kaiser, B. and Shugar, A. N. (2012) 'Glass analysis utilizing handheld X-ray fluorescence', in Shugar, A. N. and Mass, J. L. (eds) Handheld XRF for Art and Archaeology. Leuven, Belgium: Leuven University Press (Studies in Archaeological Sciences), pp. 449-470.

Kunicki-Goldfinger, J. J., Freestone, I. C., McDonald, I., Hobot, J. A., Gilderdale-Scott, H. and Ayers, T. (2014) 'Technology, production and chronology of red window glass in the medieval period - rediscovery of a lost technology', Journal of Archaeological Science, 41, pp. 89-105. doi: 10.1016/j.jas.2013.07.029.

Marks, R. (1993) Stained Glass in England during the Middle Ages. London: Routledge.

Melcher, M. and Schreiner, M. (2006) 'Leaching studies on naturally weathered potash-limesilica glasses', Journal of Non-Crystalline Solids, 352(5), pp. 368-379. doi: 10.1016/j.jnoncrysol.2006.01.017.

Newton, R. G. (1982) The deterioration and conservation of painted glass: A critical bibliography. Oxford: Oxford University Press (Corpus Vitrearum Medii Aevi Great Britain Occasional Papers II).

Pollard, A. M. and Heron, C. (1996) 'The chemistry and corrosion of archaeological glass', in Pollard, A. M. and Heron, C. (eds) Archaeological chemistry. Cambridge: Royal Society of Chemistry, pp. 149-195.

Potts, P. J., Williams-Thorpe, O. and Webb, P. C. (1997) 'The bulk analysis of silicate rocks by portable X-ray fluorescence: Effect of sample mineralogy in relation to the size of the excited volume', Geostandards Newsletter, 21(1), pp. 29-41. doi: 10.1111/j.1751908X.1997.tb00529.x.

Ringwood, A. E. (1955) 'The principles governing trace element distribution during magmatic crystallization: Part I. The influence of electronegativity', Geochimica et Cosmochimica Acta, 7(3-4), pp. 189-202. doi: 10.1016/0016-7037(55)90029-6.

Schreiner, M., Woisetschläger, G., Schmitz, I. and Wadsak, M. (1999) 'Characterisation of surface layers formed under natural environmental conditions on medieval stained glass and ancient copper alloys using SEM, SIMS and atomic force microscopy', Journal of Analytical Atomic Spectrometry, 14, pp. 395-403. doi: 10.1039/a807305h.

Scott, R. B., Shortland, A. J., Degryse, P., Power, M., Domoney, K., Boyen, S. and Braekmans, D. (2012) 'In situ analysis of ancient glass: 17th century painted glass from Christ Church Cathedral, Oxford and Roman glass vessels', Glass Technology: European Journal of Glass Science and Technology Part A, 53(2), pp. 65-73.

Shannon, R. D. (1976) 'Revised Effective Ionic Radii and Systematic Studies of Interatomic Distances in Halides and Chaleogenides', Acta Crystallographica, A 32, pp. 751-767.

Van der Snickt, G., Legrand, S., Caen, J., Vanmeert, F., Alfeld, M. and Janssens, K. (2016) 'Chemical imaging of stained-glass windows by means of macro X-ray fluorescence (MAXRF) scanning', Microchemical Journal, 124(JANUARY), pp. 615-622. doi: 10.1016/j.microc.2015.10.010.

Wedepohl, K. H. (2003) Glas in Antike und Mittelalter: Geschichte eines Werkstoffs. Stuttgart: Schweizerbart'sche Verlagsbucchandlung.

Weyl, W. A. (1951) Coloured Glasses. Sheffield, UK: The Society of Glass Technology. 